\title{
Critical challenges for EUV resist materials
}

\author{
Patrick P. Naulleau, ${ }^{1}$ Christopher N. Anderson, ${ }^{1}$ Lorie-Mae Baclea-an, ${ }^{1}$ Paul Denham, ${ }^{1}$ \\ Simi George, ${ }^{1}$ Kenneth A. Goldberg, ${ }^{1}$ Gideon Jones, ${ }^{1}$ Brittany McClinton, ${ }^{2}$ \\ Ryan Miyakawa, ${ }^{2}$ Seno Rekawa, ${ }^{1}$ and Nate Smith $^{1}$ \\ ${ }^{1}$ Center for X-Ray Optics, Lawrence Berkeley National Laboratory, Berkeley, CA 94720 \\ ${ }^{2}$ University of California, Berkeley, CA 94720
}

\begin{abstract}
Although Extreme ultraviolet lithography (EUVL) is now well into the commercialization phase, critical challenges remain in the development of EUV resist materials. The major issue for the 22-nm half-pitch node remains simultaneously meeting resolution, line-edge roughness (LER), and sensitivity requirements. Although several materials have met the resolution requirements, LER and sensitivity remain a challenge. As we move beyond the 22-nm node, however, even resolution remains a significant challenge. Chemically amplified resists have yet to demonstrate the required resolution at any speed or LER for 16-nm half pitch and below. Going to non-chemically amplified resists, however, 16-nm resolution has been achieved with a LER of $2 \mathrm{~nm}$ but a sensitivity of only $70 \mathrm{~mJ} / \mathrm{cm}^{2}$.
\end{abstract}

Keywords: extreme ultraviolet, lithography, photoresist, nanolithography

\section{INTRODUCTION}

With the delivery of extreme ultraviolet (EUV) pilot line tools now underway and manufacturing of production tools started, it is clear that EUV has progressed into the commercialization phase. Process development with these tools will require the availability of 22-nm resolution resists. Several candidates have been identified with adequate resolution, even though they do not meet ultimate line-edge roughness (LER) and sensitivity specifications. Given these milestones, advanced resist development activities have moved on to 16- $\mathrm{nm}$ and below. Such extendibility questions are best addressed using advanced research tools like the SEMATECH Berkeley microfield exposure tool (BMET) [1]. Utilizing Lawrence Berkeley National Laboratory's Advanced Light Source facility as the source of photons, the BMET benefits from the unique properties of synchrotron light enabling research at nodes generations ahead of what is possible with commercial tools. An example of the advanced capabilities afforded by the synchrotron implementation of the BMET is its lossless fully programmable coherence illuminator [2]. Using this system, resolution enhancing illuminations achieving $k_{1}$ factors of 0.25 can be attained. Given the BMET numerical aperture of 0.3 , this translates to an ultimate resolution capability of $12 \mathrm{~nm}$.

In this paper we review the progress in EUV resists and discuss critical challenges. Based on modeling and experimental results, we consider a variety of potential limiting items in EUV photoresists.

\section{STATUS OF RESIST MATERIALS FOR 22-NM HALF-PITCH}

Over the past few years, several chemically amplified resist (CAR) materials achieving 22-nm half-pitch resolution have been developed (Fig. 1). However, despite having achieved the required resolution, the LER remains a factor of 3 or more above the requirement. Moreover, the sensitivity also remains below target, but the gap is not nearly as large as for LER. Also shown in Fig. 1 are the corresponding LER, sensitivity, and Z-factor [7] numbers. The Z-factor is the resolution cubed, times the LER squared, times the sensitivity. Note that the LER values in Fig. 1 are corrected for mask effects [3-6], however, the mask impact is rather small given the elevated values of LER from the resist itself. For example, tncluding the mask effects raises the LER values in Fig. 1 by only approximately $0.2 \mathrm{~nm}$. The best material in terms of $\mathrm{Z}$ factor has an LER 2.9 times larger than the target and a sensitivity $60 \%$ lower than target. We note that the best performing resist in terms of $Z$ factor is also the earliest developed and was first reported on in 2008 [8]. 


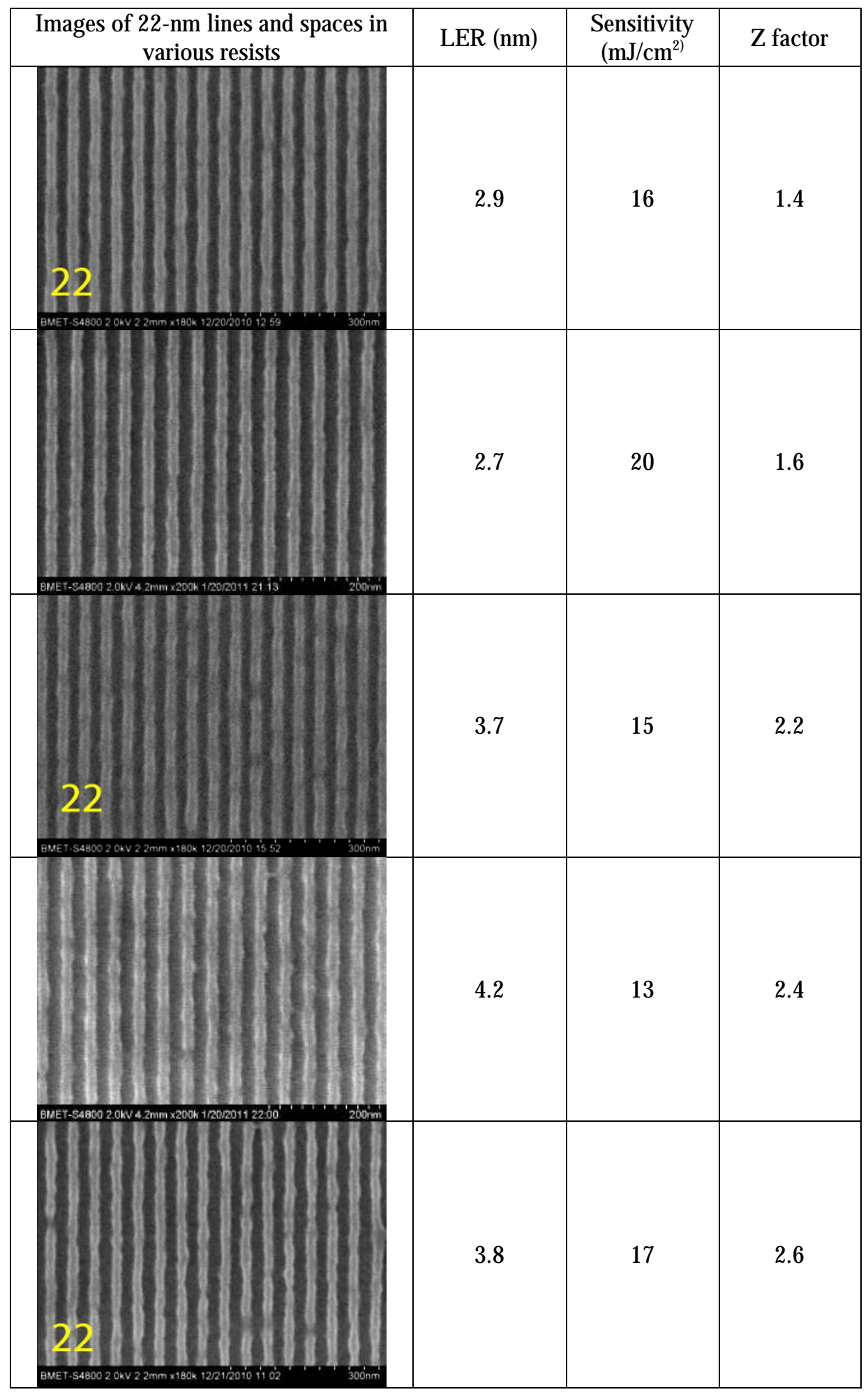

Fig. 1. Variety of EUV chemically amplified resists capable of 22-nm half-pitch resolution. The Z-factor is the resolution cubed, times the LER squared, times the sensitivity. 


\section{ULTIMATE RESOLUTION PROGRESS IN CHEMICALLY AMPLIFIED RESISTS}

As suggested above, the progress in the ultimate performance of chemically amplified resists has slowed considerably over the past few years. Figures 2 through 6 show the ultimate resolution limits in the same resists as in Fig. 1 again showing that the 2008 material performs the best. The same illumination setting was used for all resists and is a dipole optimized for 18-nm half-pitch printing.
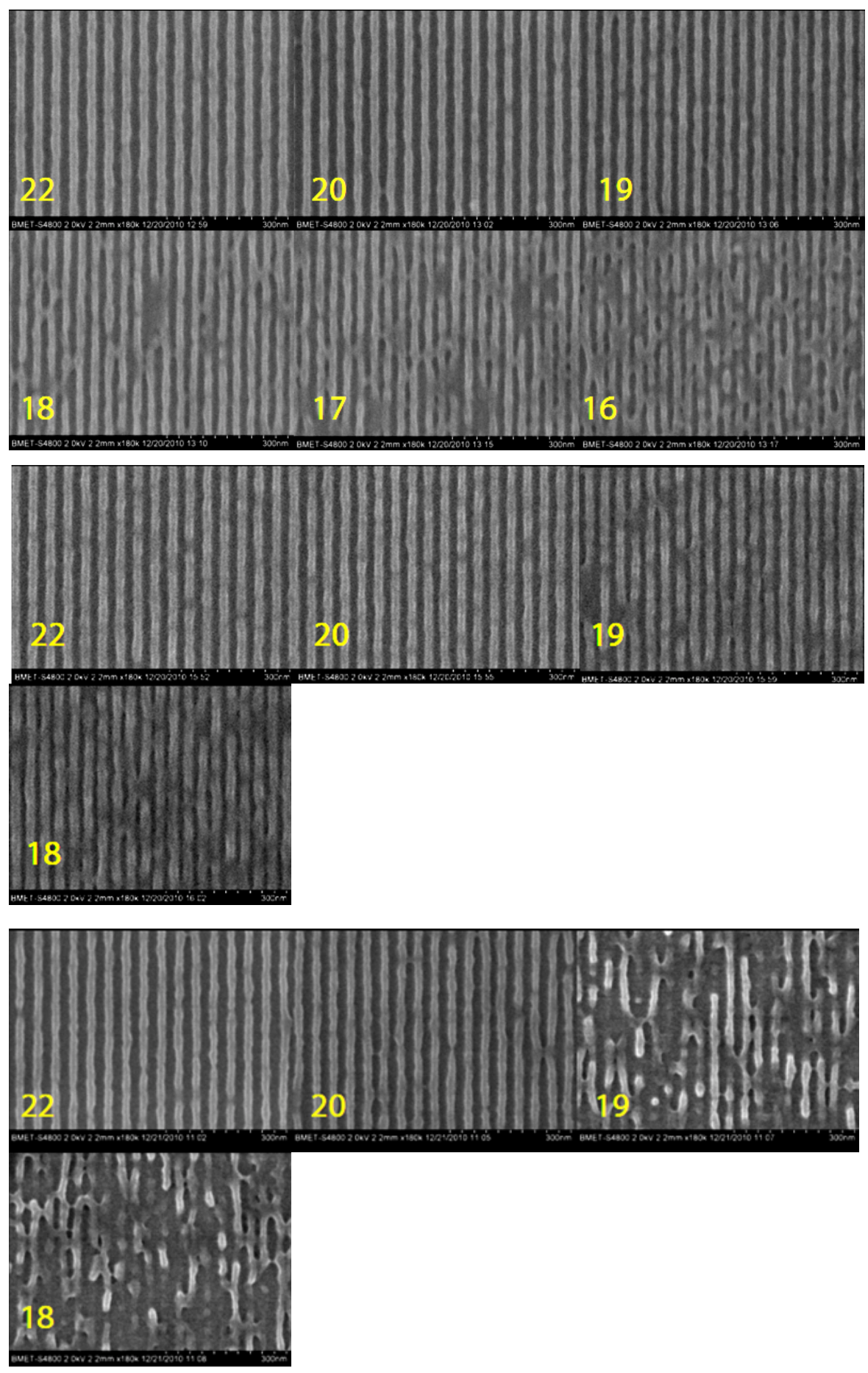

Fig. 2. Imaging results for chemically amplified resist A using the 18-nm dipole illumination.

Fig. 3. Imaging results for chemically amplified resist A using the 18-nm dipole illumination.

Fig. 4. Imaging results for chemically amplified resist A using the 18-nm dipole illumination. 

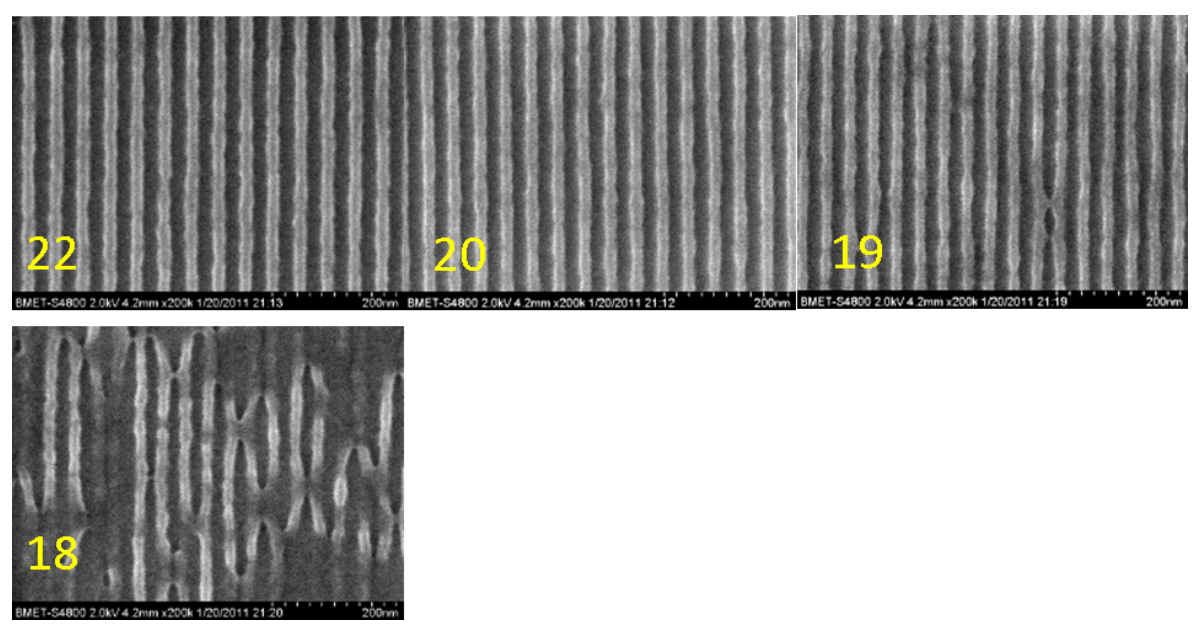

Fig. 5. Imaging results for chemically amplified resist A using the 18-nm dipole illumination.
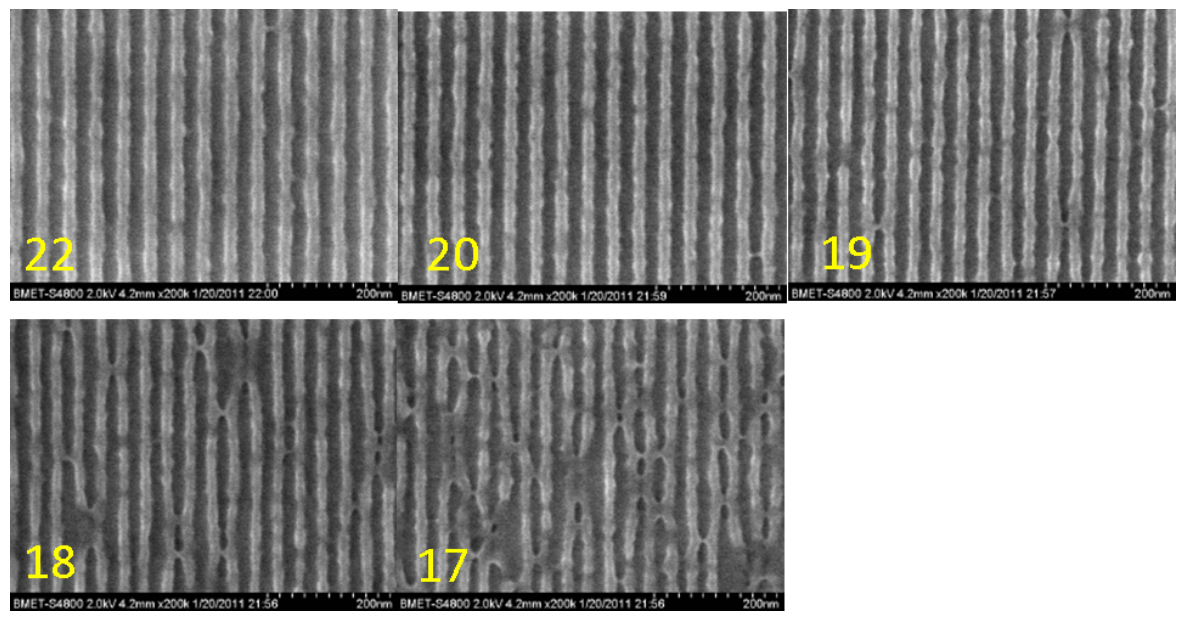

Fig. 6. Imaging results for chemically amplified resist A using the 18-nm dipole illumination.

When considering the optimized film thickness resolution limit, we find little, if any, absolute resist resolution gains in CARs. Figure 7 shows a plot of the CAR ultimate resolution as a function of year. We see strong gains early on when the SEMATECH Berkeley MET was first brought online enabling learning for the first time at resolutions of $50 \mathrm{~nm}$ and smaller, but these gains stagnated in 2008.

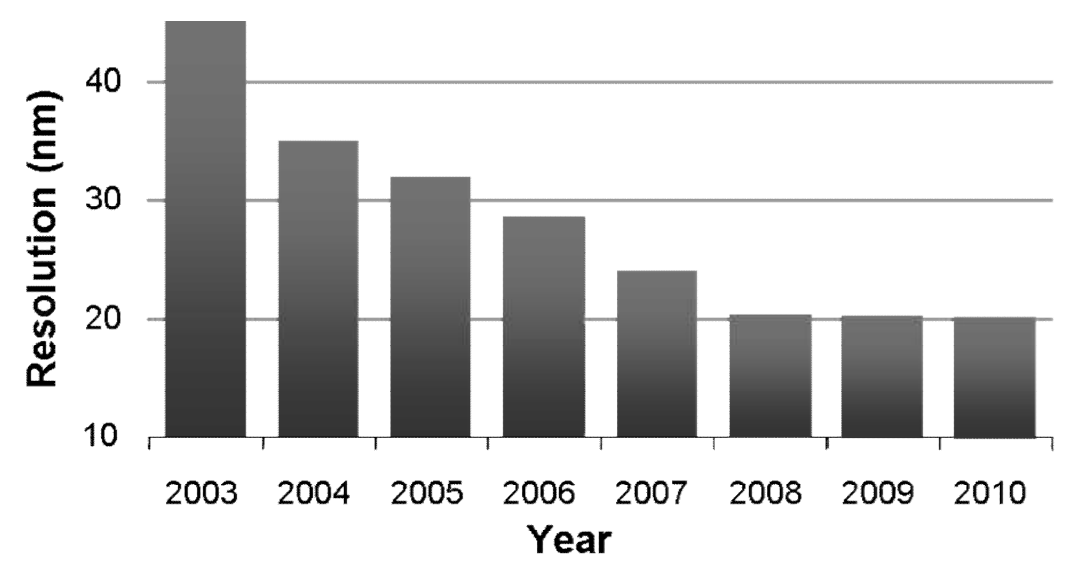

Fig. 7. Ultimate resolution as a function of year in EUV chemically amplified resists. 


\section{LER LIMITATIONS}

As described above, the biggest gap in EUV resist performance for 22-nm half-pitch is the LER. An important potential source of LER for EUV resists is photon shot noise due to the high photon energy. To study these effects a variety of shot noise models have been developed [9-12]. For the results presented below, we use the numeric implementation [10] of the analytic stochastic model first described in Ref. 9.

Figure 8 shows a scatter plot of LER performance of numerous resists tested on the SEMATECH Berkeley MET over the past 5 year. The LER data is plotted as a function of sensitivity and corrected for mask effects [3-6]. Also shown in the plot is the modeled photon-noise limited LER (solid line) using the stochastic resist model mentioned above. The model assumes a resist blur of $10 \mathrm{~nm}$, which can be shown to correspond to the near ideal blur in terms of LER for 22$\mathrm{nm}$ half pitch features. Also assumed is a resist absorptivity of $0.0042 \mathrm{~nm}^{-1}$, a thickness of $80 \mathrm{~nm}$, a quantum efficiency of 2, a PAG concentration of $0.1 \mathrm{~nm}^{-3}$, and a deprotection rate of $4 \mathrm{~nm}^{3} / \mathrm{sec}$. These values were chosen based on typical EUV CAR parameters. The sensitivity in the model was changed by varying the base loading while keeping all other parameters fixed. We note that the base-loading method for varying sensitivity is often used in experimental studies as well [13-15]. The modeling results show that resist improvement relative to the photon noise limit is still possible.

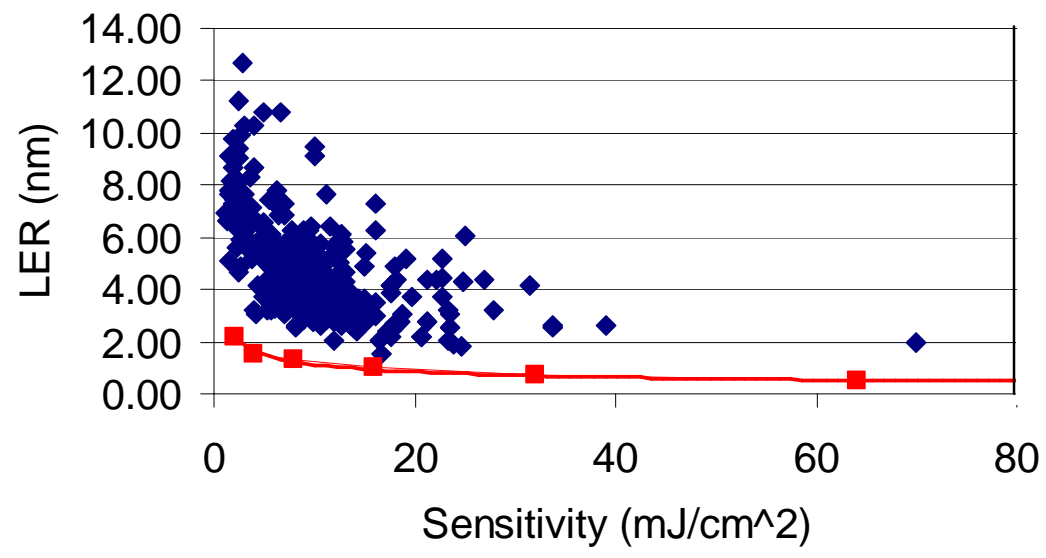

Fig. 8. Scatter plot of LER as a function of resist sensitivity and prediction of photon noise induced LER based on stochastic model.

The modeling results should not be viewed as an absolute limit since the predicted LER values can be further reduced by changing resist parameters. For example, the modeled shot-noise limited LER curve in Fig. 8 can be lowered by increasing the absorptivity of the resist. An example of this is shown in Fig. 9 where we plot the LER as a function of sensitivity and absorptivity. We see that with increased absorptivity, it is possible to increase resist sensitivity with no change in LER or loss of resolution. These results are for 11-nm half-pitch features. Other possible approaches for improved sensitivity without degradation of LER include improved acid yield and acid amplifiers [16,17]. 


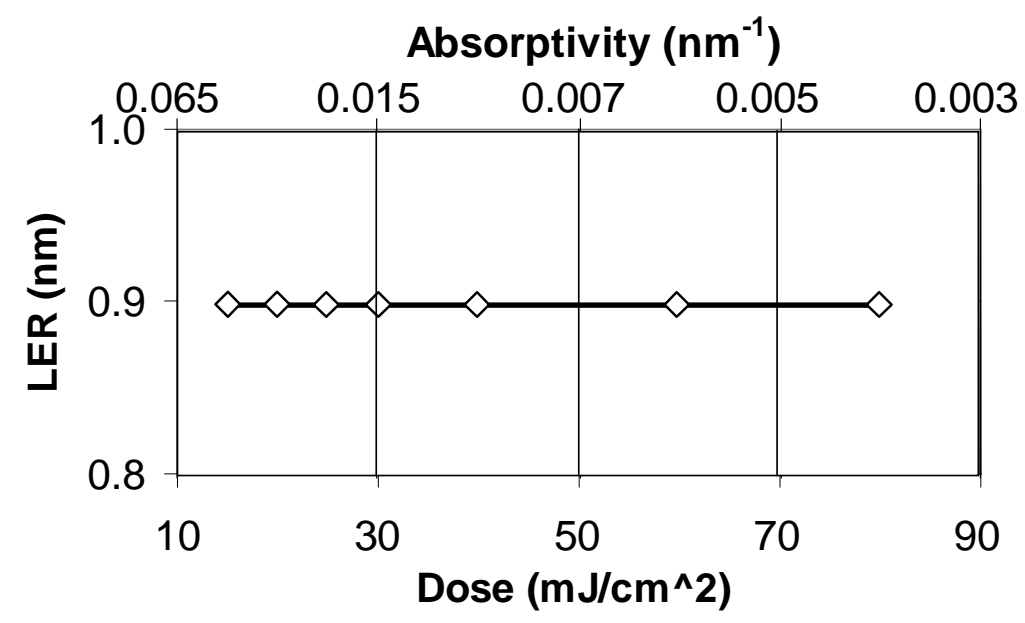

Fig. 9. Modeled LER as a function of sensitivity and absorptivity. With increased absorptivity, it is possible to increase sensitivity with no change in LER and no loss of resolution. Results are for 11-nm half-pitch features.

The results above indicate that we are not yet facing a fundamental photon noise limit; however, a limitation of the model used above is that it fails to predict interface effects. Figure 10, which shows a titled view of a radial grating feature along with a top-down view for reference, demonstrates the importance of the interface in the LER. More details on the anisotropic nature of the sidewall LER and the effects of interface engineering can be found in Ref. 18. 


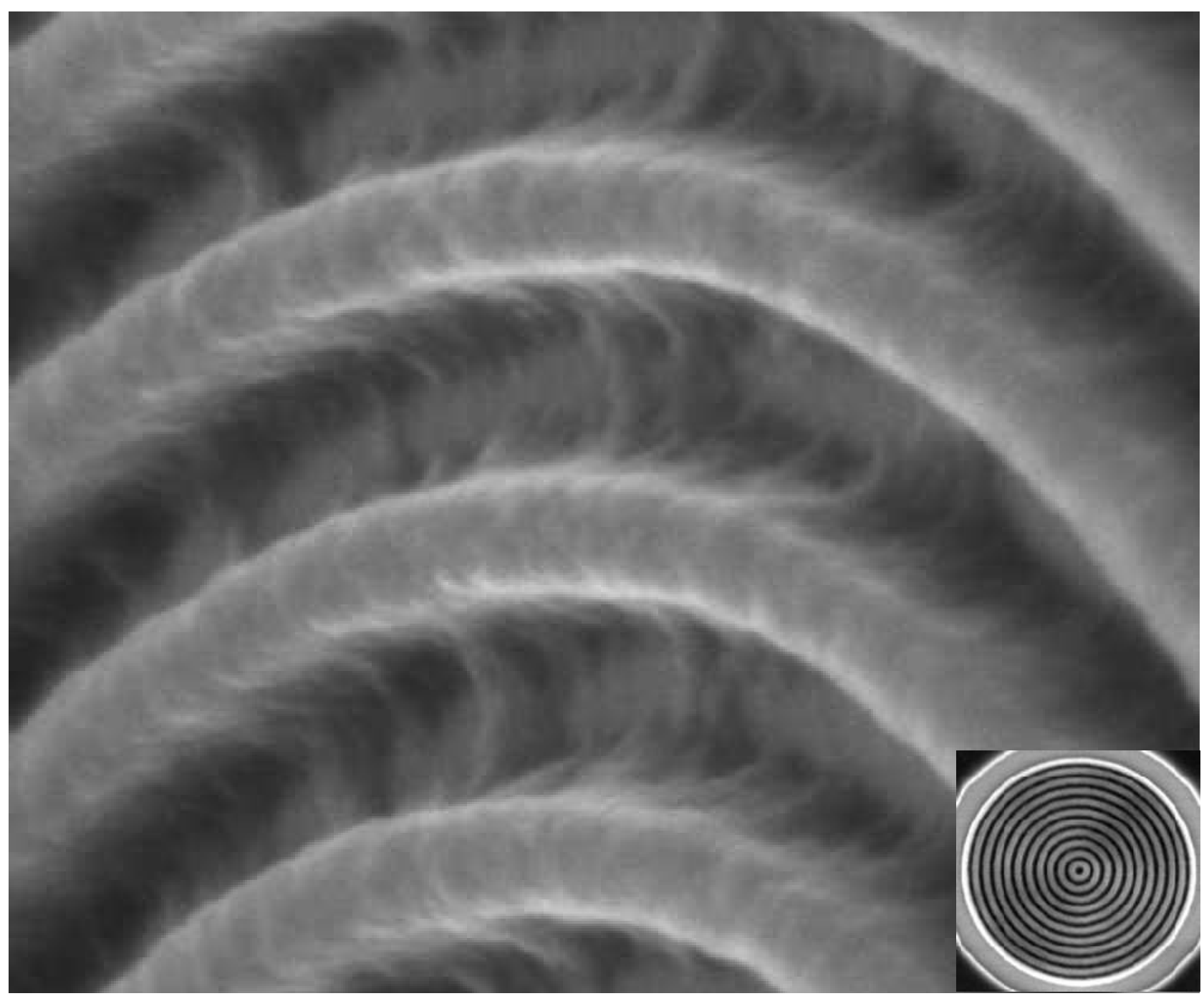

Fig. 10. Titled view of a radial grating feature, along with a top-down view for reference, demonstrating the importance of the substrate interface in the LER.

\section{OUT-OF-BAND RADIATION EFFECTS}

Being installed at a synchrotron source, the SEMATECH Berkeley MET benefits from extremely pure illumination. Although the EUV band matches that of commercial exposure tools since the EUV band is determined by the multilayers instead of the synchrotron, the vacuum and deep UV ranges are virtually non-existent. It has been hypothesized that this could account for performance differences with certain resists between the SEMATECH Berkeley MET and commercial tools. To study this effect, out-of-band illumination capabilities have been added to the BMET [19]. An example of the importance of this effect and its variance among different resist platforms is demonstrated in Fig. 11 which shows 32-nm 
lines and spaces printed with and without additional out-of-band light. The out-of-band exposure was set to be approximately $10 \%$ of the EUV exposure level and centered near 193-nm wavelength. In the case of the ArF polymer resist, the effect was so strong that no printing was observed with the additional out-of-band radiation. Figure 11 also shows the out-of-band induced change in dose to size and line-width roughness (LWR). Direct correlation between the two terms is not found.

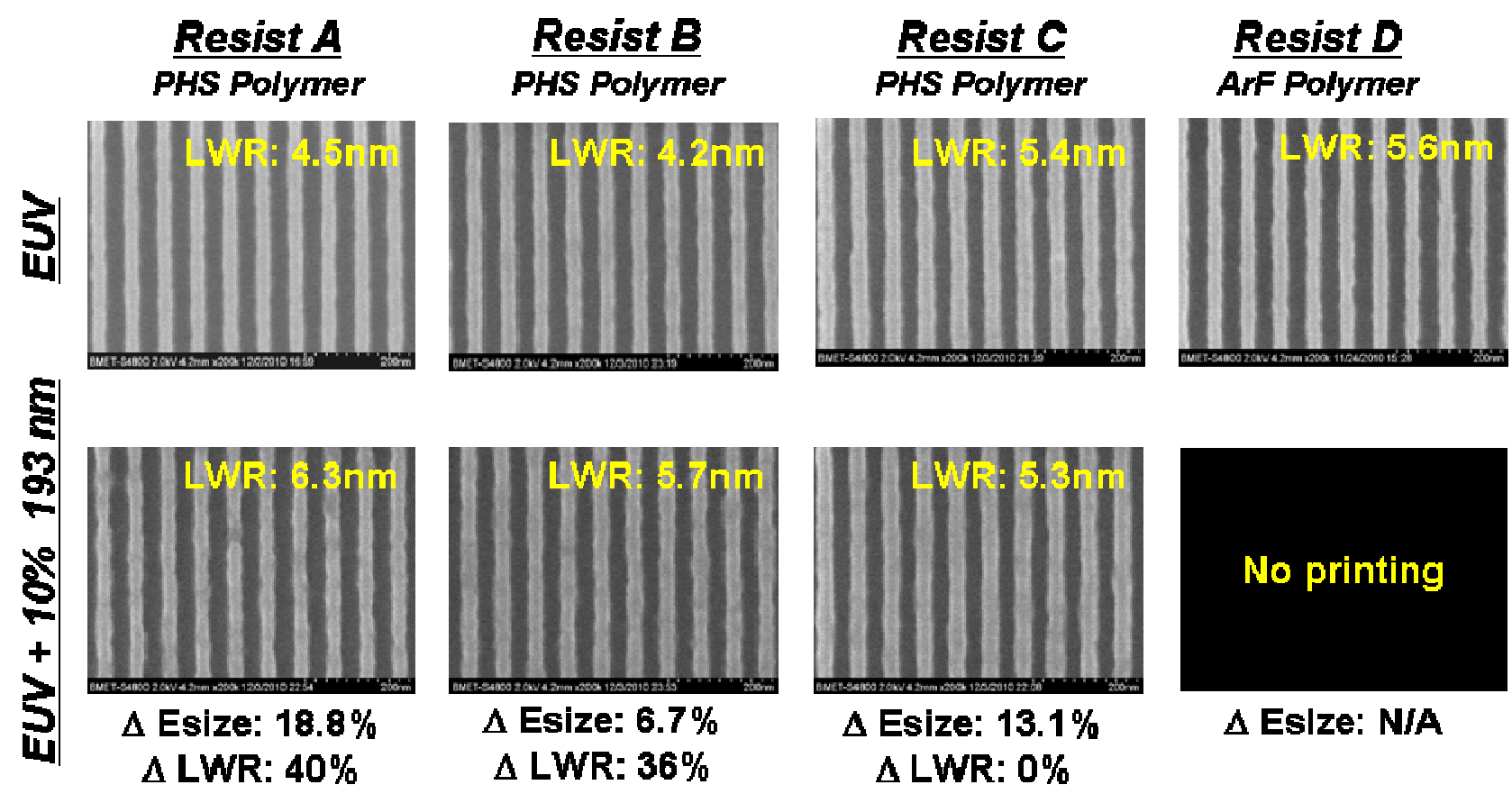

Fig. 11. 32-nm lines and spaces printed with and without additional out-of-band light. Out-of-band exposure set to be approximately $10 \%$ of EUV exposure level and centered near 193-nm wavelength. In the case of ArF polymer resist, the effect was so strong that no printing was observed with additional out-of-band radiation. Also shown is the out-of-band induced change in dose to size and line-width roughness (LWR).

\section{16 NM AND BELOW}

As discussed above, little progress has been seen in the ultimate resolution of CAR materials in the past three years. One might assume the lack of progress to be a limitation of the exposure tool rather than the resist, however, with its lossless programmable illuminator, the SEMATECH Berkeley MET is easily capable of sub-16-nm printing [20]. The ultimate resolution observed to date in BMET [21] has been achieved using a directly imageable metal oxide hardmask. Since the time those results were published, even further gains in resolution have been achieved in this material, but at the cost of sensitivity. Figure 12 shows printing results in this inorganic non-CAR material provided by Inpria [22, 23]. The sizing dose in this material is approximately $70 \mathrm{~mJ} / \mathrm{cm}^{2}$. The line-edge roughness at $16-\mathrm{nm}$ half pitch is $2.0 \mathrm{~nm}$ for spatial periods from $32 \mathrm{~nm}$ to $502 \mathrm{~nm}$ and after correction for mask effects. We note that the low in-band LER is in part due to the short correlation length of $6 \mathrm{~nm}$ (Fig. 13). 

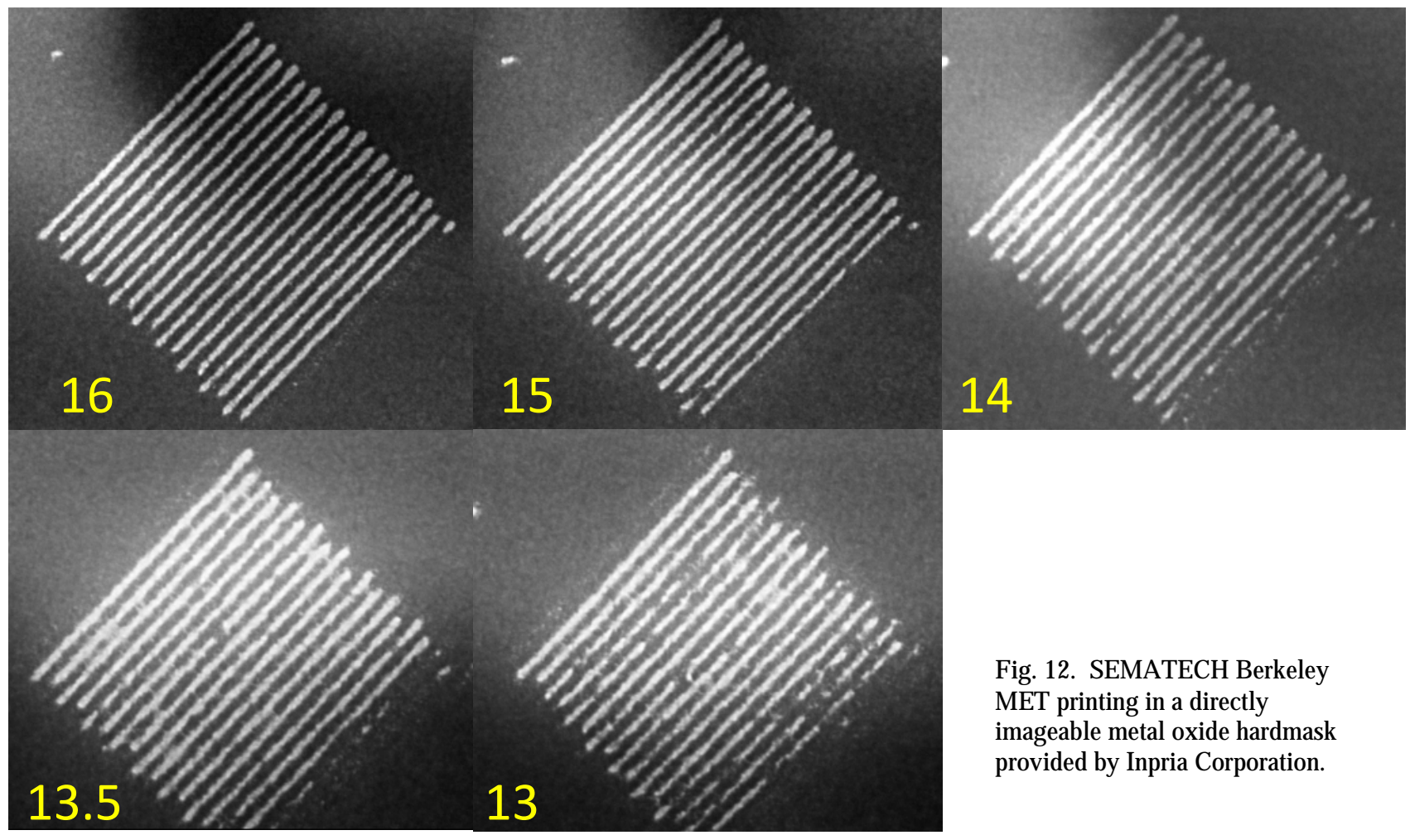

Fig. 12. SEMATECH Berkeley MET printing in a directly imageable metal oxide hardmask provided by Inpria Corporation.

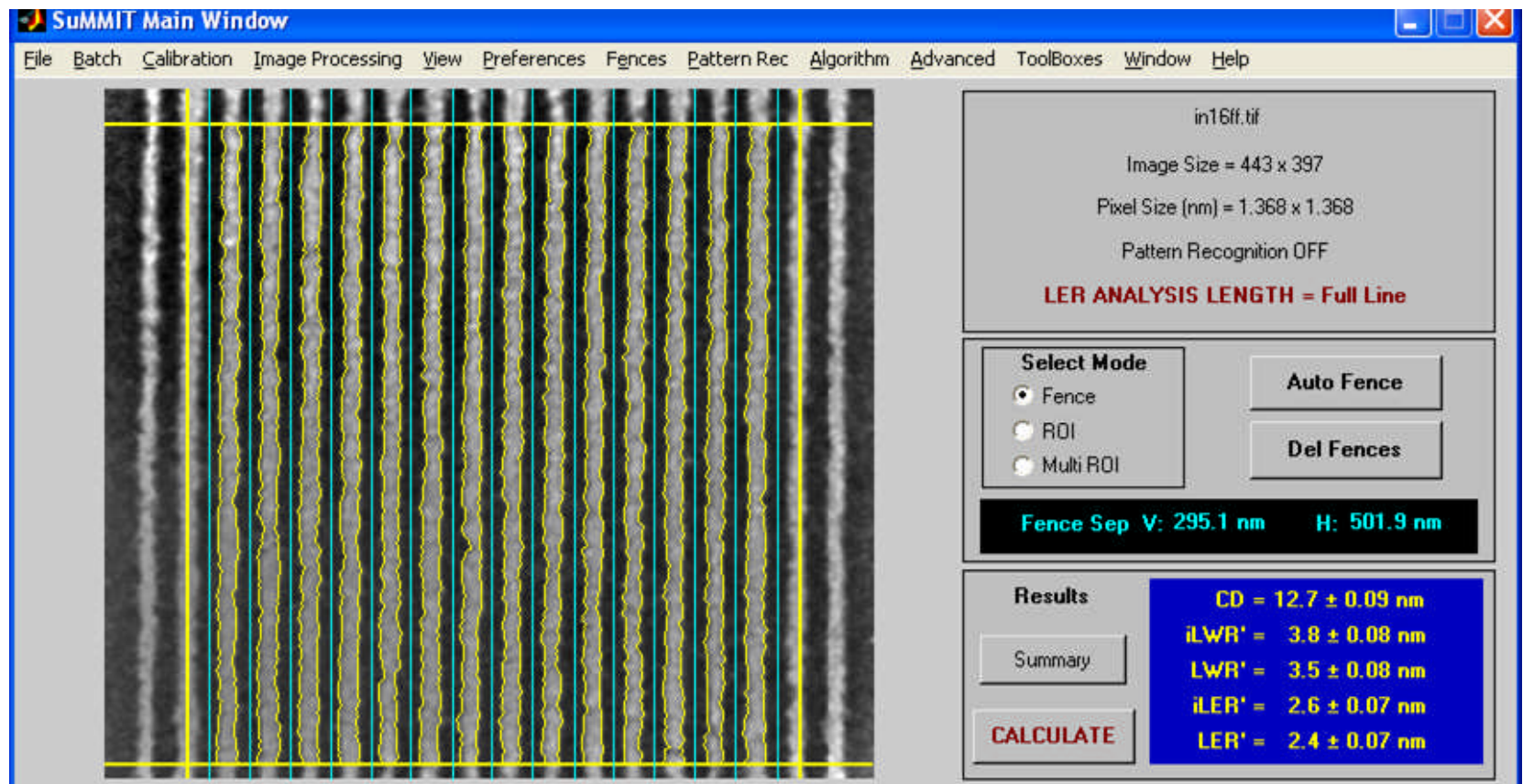

Fig. 13. LER analysis of the 16-nm lines and spaces printed in the resist from Fig. 12. The actual printed CD is $12.7 \mathrm{~nm}$ and the LER is $2.4 \mathrm{~nm}$ for spatial periods from $32 \mathrm{~nm}$ to $502 \mathrm{~nm}$. The correlation length is $6 \mathrm{~nm}$. Correction for mask effects reduces the LER to 2.0 . 


\section{SUMMARY}

Champion EUV resist resolution from a conventional projection lithography system has been pushed to below $16 \mathrm{~nm}$. This, however, was achieved in a non-CAR material. Ultimate resolution progress in CAR materials has been stalled at approximately 20-22-nm half pitch for the past three years. Also of significant concern are the high levels of LER observed in EUV resists. Stochastic modeling, however, shows that photon shot noise is not yet a limiting factor. Threedimensional visualization, on the other hand, suggests that interface effects could be playing an important role in current LER limitations. As we look to 16 and beyond, however, stochastic modeling indicates that photon noise is a significant concern. The modeling also shows that addressing this issue requires resist absorptivity to be increased.

The authors are greatly indebted to CXRO precision engineering including Kevin Bradley, Rene Delano, Jeff Gamsby, Bob Gunion, Farhad Salmassi, and Ron Tackaberry for building and maintaining the SEMATECH Berkeley MET exposure tool. We thank Gregg Gallatin of NIST for valuable discussions. We also thank Jim Thackeray and Katherine Spear of Dow Chemical, Shinji Tarutani of Fujifilm, Yoshio Kawai of Shin Etsu, and Andrew Grenville, Jason Stowers and Mike Kocsis of Inpria, and Hiroki Nakagawa of JSR for excellent resist support. We thank Ted Liang and Guojing Zhang of Intel, and Sungmin Huh of Samsung for mask support. This work was funded by SEMATECH and we thank Bryan Rice and Stefan Wurm for continued support of the SEMATECH MET exposure facility at the Advanced Light

Source. The work was performed at Lawrence Berkeley National Laboratory's Advanced Light Source synchrotron facility and was supported by SEMATECH. This work was supported by the Director, Office of Science, Office of Basic Energy Sciences, of the U.S. Department of Energy under Contract No. DE-AC02-05CH11231.

\section{REFERENCES}

1. P. Naulleau, et al, "The SEMATECH Berkeley microfield exposure tool: learning at the 22-nm node and beyond," Proc. SPIE 7271, 7271W (2009).

2. P. Naulleau, K. Goldberg, P. Batson, J. Bokor, P. Denham, and S. Rekawa, "A Fourier-synthesis custom-coherence illuminator for EUV microfield lithography," Appl. Opt. 42, 820-826 (2003).

3. P. Naulleau and G. Gallatin, "The line-edge roughness transfer function and its application to determining mask effects in EUV resist characterization," Appl. Opt. 42, 3390-3397 (2003).

4. N. Beaudry, T. Milster, "Effects of mask roughness and condenser scattering in EUVL systems," Proc. SPIE. 3676, 653-662 (1999).

5. P. Naulleau, "The relevance of mask-roughness-induced printed line-edge roughness in recent and future EUV lithography tests," Appl. Opt. 43, 4025-4032 (2004).

6. P. Naulleau, D. Niakoula, G. Zhang, "System-level line-edge roughness limits in extreme ultraviolet lithography," J. Vac. Sci. \& Technol. B 26, 1289-1293 (2008).

7. T. Wallow, C. Higgins, R. Brainard, K. Petrillo, W. Montgomery, C. Koay, G. Denbeaux, O. Wood, Y. Wei, "Evaluation of EUV resist materials for use at the $32 \mathrm{~nm}$ half-pitch node," Proc. SPIE 6921, 69211F (2008).

8. P. Naulleau, C. Anderson, J. Chiu, P. Denham, S. George, K. Goldberg, B. Hoef, G. Jones, C. Koh, B. La Fontaine, A. Ma, W. Montgomery, J. Park, T. Wallow, S. Wurm, "The SEMATECH Berkeley MET: learning at the 22-nm node," 2008 International Symposium on Extreme Ultraviolet Lithography, Lake Tahoe, CA, September 28- October 1, 2008, proceedings available from SEMATECH, Austin, TX.

9. G. Gallatin, "Resist blur and line edge roughness," Proc. SPIE 5754, 38-52 (2005).

10. P. Naulleau and G. Gallatin, "The effect of resist on the transfer of line-edge roughness spatial metrics from mask to wafer," J. Vac. Sci. Technol. B, to be published (2011).

11. S. Robertson, J. Biafore, M. Smith, M. Reilly, J. Wandell, "Predictive linewidth roughness and CDU simulation using a calibrated physical stochastic resist model," Proc. SPIE 7639, 763934 (2010).

12. C. A. Mack, "Stochastic approach to modeling photoresist development", J. Vac. Sci. Technol. B 27, 1122-1128 (2009).

13. R. Brainard, P. Trefonas, J. Lammers, C. Cutler, J. Mackevich, A. Trefonas, S. Robertson, "Shot noise, LER, and quantum efficiency of EUV photoresists," Proc. SPIE 5374, 74-85 (2004)

14. C. Szamanda, et. al., "Measuring acid generation efficiency in chemically amplified resists with all three beams," J. Vac. Sci. Technol. B 17, 3356-3361 (1999); 
15. Adam R. Pawlowkski, A. Acheta, H. Levinson, T. Michaelson, A. Jamieson, Y. Nishimura, C. Willson, "Line edge roughness and intrinsic bias for two methacrylate polymer resist systems", J. Microlith. Microfab. Microsys. 5, 023001 (2006).

16. C. Higgins, A. Antohe, G. Denbeaux, S. Kruger, R. Brainard, Jacque Georger, "RLS tradeoff vs. quantum yield of high PAG EUV resists." Proc. SPIE 7271, 727147 (2009).

17. R. Brainard, S. Kruger, C. Higgins, S. Revuru, S. Gibbons, D. Freedman, W. Yueh, T. Younkin, "Kinetics, Chemical Modeling and Lithography of Novel Acid Amplifiers for Use in EUV Photoresists," J. Photopolym. Sci. Technol. 22, 43-50 (2009).

18. Simi A. George, Patrick P. Naulleau, Benjamin Z. Y. Wu, Joseph T. Kennedy, Song-Yuan Xie, Kyle Y. Flanigan, Thomas I. Wallow, "Characterization of line-edge roughness (LER) propagation from resist: underlayer interfaces in ultra-thin resist films," Proc. SPIE 7636, 763605-1 (2010).

19. S. George, P. Naulleau, "Out of band radiation effects on resist patterning," Proc. SPIE 7969, these proceedings (2011).

20. C. Anderson, P. Naulleau, L. Baclea-an, P. Denham, S. George, K. Goldberg, G. Jones, B. McClinton, W. Montgomery, N. Smith, T. Wallow, "The SEMATECH Berkeley MET: extending EUV learning down to 16-nm half pitch,” Proc. SPIE 7969, these proceedings (2011).

21. P. Naulleau, C. Anderson, L. Baclea-an, S. George, K. Goldberg, B. Hoef, M. Jones, C. Koh, B. La Fontaine, W. Montgomery, T. Wallow, "The SEMATECH Berkeley MET pushing EUV development beyond 22-nm half pitch," Proc. SPIE 7636, 76361J-1 (2010).

22. Material provided by A. Grenville and J. Stowers, Inpria Corporation, 2001 NW Monroe Ave Corvallis, OR 97330.

23. J. Stowers, A. Telecky, D. Keszler, A. Grenville, P. Naulleau, C. Anderson, "Directly patterned inorganic hardmask for EUV lithography," Proc. SPIE 7969, these proceedings (2011). 


\section{DISCLAIMER}

This document was prepared as an account of work sponsored by the United States Government. While this document is believed to contain correct information, neither the United States Government nor any agency thereof, nor The Regents of the University of California, nor any of their employees, makes any warranty, express or implied, or assumes any legal responsibility for the accuracy, completeness, or usefulness of any information, apparatus, product, or process disclosed, or represents that its use would not infringe privately owned rights. Reference herein to any specific commercial product, process, or service by its trade name, trademark, manufacturer, or otherwise, does not necessarily constitute or imply its endorsement, recommendation, or favoring by the United States Government or any agency thereof, or The Regents of the University of California. The views and opinions of authors expressed herein do not necessarily state or reflect those of the United States Government or any agency thereof or The Regents of the University of California. 